\title{
Research on Effects of Science \& Technology Progress on Shaanxi Economic Development
}

\author{
Li Guo (Corresponding author) \\ School of Management \\ Xi'an University of Science and Technology \\ Xi'an 710054, China \\ Tel: +86-139-0925-0069 E-mail: christie_guo@163.com \\ Jinsuo Zhong \\ Energy Economy and Management Research Center \\ Xi' an University of Science and Technology \\ Xi'an 710054, China \\ Tel: +86-029-8558-3906Ｅ-mail: liyaguo@sina.com
}

Received: December 5, 2011

Accepted: January 9, 2012 Published: March 15, 2012

doi:10.5430/ijba.v3n2p47

URL: http://dx.doi.org/10.5430/ijba.v3n2p47

This paper is funded by the National Soft Science Program (2006GXQ3D160), the Key Project of Shaanxi Soft Science Research Program (2010KRZ02), and the Science and Research Cultivation Foundation of Xi'an University of Science \& Technology (2010014).

\begin{abstract}
Based on reviewing and analyzing the situations of Shaanxi science \& technology progress and economic development, and researching the concept and connotation of contribution rate of science \& technology progress, authors reference data of Shaanxi economy, capitals, and labors from 1978 to 2008 and use the Solow's residual method to calculate the contribution rate of science \& technology progress in Shaanxi province at different periods of time: 1979-1988, 1989-1999, 2000-2008. From the technological point of view, authors propose relevant policies and suggestions for the economic and social sustainable development in Shaanxi province.
\end{abstract}

Keywords: Science \& technology progress, Contribution rate, Economic development, Solow's residual method, Calculation

Science \& technology progress is the primary driving force to the economic and social development in the $21^{\text {st }}$ century. However, science \& technology promoting economic and social development has always been the development bottleneck of science \& technology in Shaanxi province. In recent years, the investment in scientific and technological activities in Shaanxi province has ranked ahead of the nation, but the output of scientific and technological activities and the promotion of science \& technology to economic and social development are below the average of China. "The National and Regional Statistic Monitoring Results of Scientific and Technological Progress in 2008" from the Ministry of Science and Technology of China shows that in the year 2008 the index of Shaanxi's investment in science \& technology ranked No.7 in the country, the index of scientific and technological output was $10.54 \%$ lower than the average, the index of science \& technology promoting economic and social development ranked No.18, which was $5 \%$ lower than the average, and the index of integrated science \& technology progress level was $4.87 \%$ lower than the average in China. The existence of "Shaanxi Phenomenon" of good at science \& technology but poor in economy, in which the progress of science \& technology is slowing and the contribution rate of science \& technology progress is consistently low, becomes the focus of the country and the practical problem, which needs to be settled carefully by the Shaanxi provincial government. Therefore, Shaanxi provincial government suggests that the "Twelfth Five-Year Plan" for national economic and social development should follow the scientific outlook on development, and take the fast development as the main line and the scientific and technical innovation as the guideline. Continue to strengthen the 
support from science \& technology for economic and social development, improve the contribution rate of science \& technology progress to economic growth, and make science \& technology to play the role of primary productive force, driving the transformation of Shaanxi's advantages in science \& technology to advantages in economy.

Science \& technology progress is the key element determining the future economic and social development in Shaanxi province. The calculation of contribution rate of science \& technology progress has an important reference value for developing regional economic and social development strategy and macro economic management. Therefore, to calculate the contribution rate of science \& technology progress and compose the key strategy of improving the rate of science \& technology progress and the contribution rate of science \& technology in Shaanxi province will be meaningful in theory and practice. By this way, it can help to achieve the strategic goal of science \& technology development in Shaanxi province that the contribution rate of science \& technology progress is above 50\% in 2012 and $60 \%$ in 2020 .

\section{The Concept and Connotation of Contribution Rate of Science and Technology Progress}

The contribution rate of science \& technology progress is the proportion of economic growth caused by science \& technology progress. It is the ratio of the speed of science \& technology progress to the speed of economic growth. However, because there is not a consensus about the connotation of science \& technology progress in the theoretical field, experts hold different opinions towards the specific connotations of contribution rate of science \& technology progress.

What is on earth the science \& technology progress? Different economists have different views. Solow excludes the two factors, namely capitals and labors, that constrain the economic growth, and takes other factors causing economic growth, such as science \& technology, improvement of organization and management, scale economy, better resource allocation, as science \& technology progress. That is the broad concept of science \& technology progress (Solow, 1957). Lucas (2003) thinks that science \& technology, differing from knowledge in a general sense, is the knowledge of specific populations, or the sub-culture of specific populations. It is something determined by factors beyond our current understandings. Romer emphasizes that science \& technology, as a special input, is different from human resources. It is either traditional commodity or pure public goods. It is non-competitive and partial exclusive.

Qingqi Shi thinks that science \& technology progress is a process in which science \& technology, together with other factors, make certain combination of production factors to achieve more output. The content of science \& technology progress includes: (1) Improve the technical level of equipments and products; (2) Reform the production process; (3) Improve the quality of workers; (4) Improve the decision-making level of management (Qingqi Shi \& Baoting Qin, 1994).

Angzhao Di says: "The concept of science \& technology progress (also known as total factor productivity) has been clearly defined in economics. Its effect on economic growth has proved by rigorous theories and described by mathematic model. These studies are more mature and already in textbooks of economics (Samuelson, 1986, 'Economics', The Commercial Press)." He believes that the concept of science \& technology progress has different connotations in different circumstances. At the micro level of enterprises, the connotations of science \& technology (as the factor neutralizing the law of diminishing returns) mainly include the use of new equipments, new technologies, the improvement of workers' skills, which is close to the intuitive understanding of science \& technology progress. At the macro level of nation or region, the connotation of science \& technology progress includes not only the contents at the micro level, but also other parts, such as the adjustment of industrial structure, the optimization of economic structure, etc. (Angzhao Di, 1997).

Weiguo Song and Jun Li believe that the basic concept of science \& technology progress origins from the economists' studies of production functions. In production functions, capitals, labors, and science \& technology progress are the main factors influencing economic yield. Suppose $\mathrm{Y}=\mathrm{Y}(\mathrm{K}, \mathrm{L})$ is the production function. Here, $\mathrm{Y}$ is yield, $\mathrm{K}$ is the capital input, $\mathrm{L}$ is the labor input, and $\mathrm{T}$ is the time. Then,

$\mathrm{V}_{\mathrm{T}}=\frac{\partial \mathrm{Y} / \partial \mathrm{T}}{\mathrm{Y}}=\frac{\partial \ln Y}{\partial T}$

It is the growth rate of science \& technology progress. The growth rate of science \& technology progress is described as the growth rate of yield caused by changes of time as other factor inputs are in the same situation. Because the change of $\mathrm{Y}$ includes the integrated change of all factor inputs, it is known as the growth rate of total factor productivity in economics. The total factor productivity is the most universal concept reflecting science \& technology progress. He also suggests that the concept of science \& technology progress has broad and narrow sense. Therefore, the broad contribution rate of science \& technology progress integrates the contribution of all other factors (such as mechanism, system, mangement, science \& technology application, etc.), except two main factors, capitals and labors, to economic 
growth. Only when other factors do not change or affect samll, can it be regard as the contribution rate of pure science \& technology. That is the narrow sense of contribution rate of science $\&$ technology progress.

\section{The Calculation of Contribution Rate of Science \& Technology Progress in Shaanxi Province}

\subsection{Model Selection}

In this paper, authors use the Solow's residual method, created by an American economist Solow, the founder of the growth theory of neoclassical economics, to calcualte the contribution rate. The formula

$a=y-\alpha k-\beta l$

Under the circumstance of no changing returns to scale,

$\alpha+\beta=1$

$\mathrm{E}_{\mathrm{a}}=\frac{a}{y}$

It is the contribution rate of science \& technology progress. Therefore, in this paper authors, what the authors calculate is the contribution rate of science \& technology progress in a broad sense. $\mathrm{E}_{\mathrm{k}}$ is the contribution of capitals to the growth rate of yield, and $\mathrm{E}_{1}$ is the contribution of labors to the growth rate of yield. Here,

$\mathrm{E}_{\mathrm{k}}=\alpha \frac{\mathrm{k}}{y}$

$\mathrm{E}_{\mathrm{a}}=\frac{a}{y}$

\subsection{The Establishment of Data Indicators and Elasticity Coefficient}

\subsubsection{The Establishment of Data Indicators}

a. The Establishment of Yield Indicator

In this paper, authors select the GDP of Shaanxi province as the economic yield indicator and take the year 1952 as the base period. Results are in Table 1.

b. The Establishment of Capital Input Indicator

The capital input should be the total capital stock that directly or indirectly forms the production capacity. It includes all kinds of fixed assets and current assets that serve the production with materials and labors, and the assets that provide a variety of services for living and welfare facilities, such as houses. According to researches of scholars, as for the capital input, there are big differences in the selection of indicator. Many scholars choose the capital stock as the capital input. Some choose the fixed capital stock, fixed asset consumption, fixed asset depreciation, and fixed asset investment as the capital input. However, among these indicators, except that the data of fixed asset investment is available in statistic yearbook, data of others needs to be calculated to get. Considering the reasonability of data calculation, authors choose the capital stock of Shaanxi province as the capital input indicator. Specific data is from the research of Jun Zhang (Jun Zhang, Guiying Wu \& Jipeng Zhang, 2004). Take the year 1952 as the base period and use the perpetual inventory method in calculation. Results are in Table 1.

\section{c. The Establishment of Labor Input Indicator}

The factor input of production function, strictly following the theoretical requirements, should be the "flow of services". It depends on not only the quantity of factor input, but also the quality and the efficiency of utilization. As for the labor input indicator, foreign and domestic studies show that there are four ways to establish the labor input, namely the number of labors, the labor remuneration, the labor time, and the average education level. Considering the availability and the objectivity of statistical data, we select the number of labors as the labor input indicator. Results are in Table 1.

\subsubsection{The Establishment of Elasticity Coefficient}

In the calculation of elasticity coefficients of capitals and labors, most scholars use regression analysis, theoretical analysis, and empirical determination. The regression analysis method is based on the growth rate equation, using the generalized least squares method to estimate the parameters. That is the most widely used method. It is a pure mathematical and statistical method, with unclear economic meanings, requiring a great number of data, and not easy to control errors. The theoretical method is to make certain reasonable assumption for the production process from an economic sense. However, these assumptions are often too far away from the actual situations, which cause sharp different results. The empirical determination is to regulate the value of factor elasticity coefficient based on experiences and analysis. For example, the former National Planning Commission has determined the range of elasticity of capitals and labors in files. This method has its advantages since it is easy to calculate and popularize. However, because the determination of factor elasticity coefficient has not solid theoretical basis, scholars choose to modify the factor 
elasticity coefficient once not get the expected results. As a result, the calculation of contribution rate of science \& technology progress is random (Jinyi He, 2006; Abramovitz \& Paul A. David, 2000). A scholar Ximing Dong uses the substitution method to calculate the factor elasticity coefficient. However, whether it is a scientific method needs to be discussed further. Considering all these factors, in this paper, authors use the regression method to calculate the yield elasticity coefficient of capitals and labors.

The production function:

$Y=A K^{\alpha} L^{\beta}$

Take the logarithm of two sides respectively,

$L N(Y)=L N(A)+\alpha L N(K)+\beta L N(L)$

In regression, suppose the returns to scale do not change, namely $\alpha+\beta=1$, then the formula (8) becomes:

$L N\left(\frac{Y}{L}\right)=L N(A)+\alpha L N\left(\frac{K}{L}\right)$

2.3 The Calculation Result of Contribution Rate of Science \& Technology Progress in Shaanxi Province and the Result Analysis

Based on the statistical data of Shaanxi province from 1978 to 2008, authors use the formula (9) and SPSS to make a regression analysis of yield elasticity of capitals and labors respectively. The result is:

$L N\left(\frac{Y}{L}\right)=e^{1.140}+0.765430 L N\left(\frac{K}{L}\right)$

Here, the yield elasticity of capital is $\alpha=0.75643$ and the yield elasticity of labor is $\beta=0.24357$. Then,

$R=0.958 、 R^{2}=0.917 、 \overline{R^{2}}=0.915 、 S=0.29603 、 D W=0.116 、 F=607.165 、 P<0.001$

Results show that the values of parameters are significant in statistics.

Input data of Table $1, \alpha=0.75643$ and $\beta=0.24357$ into formula (2), (4), (5), (6), and calculate by stages.

Table 2 shows that the contribution rate of labor growth to economic growth in Shaanxi province from 1978 to 1988 is $6.67 \%$, the contribution rate of capital growth to economic growth is $66.07 \%$, and the contribution rate of science \& technology progress is $27.16 \%$. During this period, the development of economy mainly depends on capital inputs. It is an epitomical growth of economy.

From 1989 to 1999 , the contribution rate of labor growth to economic growth drops to $4.01 \%$, and the contribution rate of capital growth to economic growth fells by $15 \%$. Because the government intensifies the management over science \& technology and issues relevant policies and measures, the contribution rate of science \& technology progress to economic growth rises by $18 \%$. During this period, capital input and science $\&$ technology input are important for the development of Shaanxi economy. The economy of Shaanxi province grows in a connotative mode by technological progress and efficiency improvement.

Since the year 2000, the application of western development strategy has attracted a large influx of capitals. Therefore, from 2000 to 2008, the contribution rate of capital growth to economic growth increases by $5 \%$. The contribution rate of science \& technology progress is almost at the same level. The contribution rate of labor growth to economic growth continues to decline.

During the thirty years from 1978 to 2008, the contribution rate of labor growth to economic growth in Shaanxi province is $4.54 \%$, the contribution rate of capital growth to economic growth is $63.83,13$ times higher than the former. During the same period, the contribution rate of science \& technology progress is $31.63 \%$. The proportion of contribution rates of capitals, science \& technology, and labor is 14:7:1. It indicates that since the reform and opening up, the main dynamic forces for Shaanxi economic development are from capital input and science \& technology input. Considering the contribution to economy, capital input contributes more to the economic growth than science \& technology input does.

\section{Policies and Suggestions}

Along with the continuous development of Shaanxi economy, long-term epitomical growth mode causes the gradual dry of land, mines, and other irreplaceable resources and the serious damages in ecological environment. The unsustainable development of economy has become increasingly prominent. Under this circumstance, the only feasible way to achieve the sustainable growth of economy is to depend on technological progress and higher efficiency of resource utilization, achieving higher growth rate with lower inputs, and improving the capacity of resources, environment, and ecology to economic growth. Considering Shaanxi's conditions, we can improve the contribution rate of science \& technology progress and promote the sustainable development of Shaanxi economy from the following aspects. 
First, adjust industrial structure and optimize the allocation of resources. Continue to strengthen the advantage industries, develop new industries, and reform traditional industries. For the energy and chemical industry, we should grasp the chance of China building large demonstration coal base in the north of Shaanxi to promote the "Three Integration", and strengthen the four industries, coal, oil and gas, electricity, and chemical. For the nonferrous metal industry, we can further extend the industrial chain, adopt new technologies and techniques, develop the high-end application material and equipment manufacture industry, and promote the transformation of nonferrous metal industry from sale of pure materials to production of delicate facilities. For the equipment manufacturing industry, we should focus on the production of large aircraft, especially developing the industry of computer numerical control machine tools, the industry of automobiles and parts, the industry of power transmission equipment, the industry of electronic information and components, the industry of construction machinery, and the industry of special equipment. Develop the equipped industries overall and achieve the general rise of whole equipment manufacturing industry. Make best use of Shaanxi's advantages in rich silicon resources, advanced polysilicon purification technology, and more complete photovoltaic industry chain, and accelerate the development of solar photovoltaic industry. Speed up the construction of "three logistics parks, then logistics distribution centers, two logistics platforms, and four logistics platform systems".

Second, reform the government functions, improve the macro economic control, and avoid repetitive construction and waste of social resources. Make the government focus on overall planning, policy development, information direction, organization and coordination. The government should make science \& technology policies, play a coordinating role in economic development, and help to form a policy environment with appropriate laws and an environment for scientific and technological innovation, encouraging knowledge innovation and technological innovation, and respecting knowledge and talents. Develop policies to promote the development of high-tech industry. Form talent introduction policies, incentive policies for scientists and technologists, and policies for the industry- university-institution base founded by the government, universities, scientific research institutions, and enterprises. Make best use of advantages of the government as the information center and the service center. The government can do a better organizational and coordinative job in the public fields, such as information exchange, support and guidance, resource share, and expert consultant.

Third, enhance the incentives and gather outstanding talents. Talent has a decisive effect on the development of science $\&$ technology. We must adhere to the people-oriented thought, actively creating conditions, establishing and perfecting the talent incentive policies, and promoting the technological innovation of scientists and technologists. Train a group of leading talents, qualified talents in urgent needs, key talents, and practical talents. Develop intellectual property laws that focus on the benefits of scientific research results and the distribution of benefits from the fruit transformation. Improve and perfect the incentive system for the scientific and technological fruits and the interest distribution system for the technological innovation. Encourage scientists and technologists to use their intellectual properties to invest in scientific and technological enterprises and become rich by their intelligence. Mobilize the enthusiasm of scientists and technologists fully. Establish and regulate the talent flow system and protect the reasonable flow of talents.

Fourth, increase investments in science \& technology and promote continuous innovations. Take effective measures to adjust the investment and financing structure, encourage and guide the whole society to invest more in science \& technology by all channels at different levels. Form a diversified investment and financing system for science \& technology, in which the government investment as the guidance, the business investment as the main part, the bank credit as the support, the social financing and foreign investment as the complement. In the future, try to build an effective mechanism for the steady rise of long-term fiscal investment in science \& technology, encourage scientific research institutions and enterprises to invest more in scientific research. Improve the government's ability of mobilizing and allocating all scientific and technological resources in society, and increase the amplification effect of scientific research level and government investment in science \& technology. Continue to expand the financing channels for science \& technology, improve the guarantee system for investment and financing, develop the venture capital industry in science \& technology field, and absorb foreign capitals and private funds to support the science \& technology. Increase the investment in the development of key technologies, such as energy and chemical, equipment manufacture, food, and nonferrous, which have an important impact on industrial technology progress.

Fifth, grasp independent innovation and enhance core competencies. Take the improvement of independent innovation as the central part in promoting industrial adjustment and optimization upgrade. Promote original innovation, integrated innovation, and introduce-consumption-absorption re- innovation. Strengthen the construction of technological innovation system, which takes enterprises as the main part and market as the guidance, combining industries, universities, and research institutions together. Focusing on industrial structure adjustment and upgrade, we should support the construction of public technological service platform, the construction of corporate technological center, and the innovations and researches with independent intellectual property right. We can take advantages over Shaanxi's lots of universities and scientific research institutions to promote the great development of economic zone.

Sixth, develop circular economy and improve ecological environment. Explore the development mode of regional circular economy, especially focus on the energy and chemical base in the north of Shaanxi and the industrial gathering area of circular economy in the south of Shaanxi, and crack the tough development problems in area with fragile 
environment and ecological protection area. Develop and construct pilot industrial parks for circular economy, especially Hanzhong industrial cluster of circular economy, Shangdan economic parks for circular industry, and Yanchang Petrolum Group demonstration garden for circular economy. Accelerate the development of new environmental protection industry, encourage enterprises to make full use of industrial waste, achieve the effective and circular use of resources, enhance scientific and technological researches, and make supportive policies, providing strong supports for the development of circular economy.

\section{Reference}

Abramovitz, P. \& David, A. (2000). American Macroeconomic Growth in the Era of Knowledge Based Progress: The Long-Run Perspective. Cambridge: University Press. 1-92.

Di, A. (1997). Standardization of Science and Technology Contribution Rate. Forum on Sicence and Technology in China. 3, 38-39.

He, J. (2006). Several questions need to be noticed in the calculation of contribution rate of science and technology progress. Academic Research.2, 18-19.

National Bureau of Statistics of China. (2004-2008). Calculation of Science and Technology Progress Rate and Contribution.

Shi, Q. \& Qin, B. (1994). Measure the effects of technical progress on economic growth. Studies in Sicnece of Scence. 1, p25-26.

Solow, R W. (1957). Technical change and the aggregate production function. Review of Economics and Statistics. 39.

Song, W. \& Li, J. (2000). Analysis on target option for S\&T contribution rate for the Tenth Five-Year Plan. Forum on Sicence and Technology in China. 6, 1-2.

Xu, Y., Chen, X. \& Liu, F. (2006). Estimating and decomposing the contribution of technical change in China. Economic Research Journal. 8, 93-100.

Zhang, J., Wu, G. \& Zhang, J. (2004). The estimation of China's provincial capital stock: 1952-2000. Economic Research Journal. 10, 42-43.

Table 1. Data of indicators used to calculate the contribution rate of science $\&$ technology progress in Shaanxi province from 1978-2008.

\begin{tabular}{|c|c|c|c|c|c|c|c|}
\hline Time & $\begin{array}{c}\text { GDP } \\
(100 \\
\text { million } \\
\text { RMB })\end{array}$ & $\begin{array}{c}\text { Employees } \\
(10,000)\end{array}$ & $\begin{array}{c}\text { Capital } \\
\text { stock }(100 \\
\text { million } \\
\text { RMB })\end{array}$ & Time & $\begin{array}{c}\text { GDP } \\
(100 \\
\text { million } \\
\text { RMB })\end{array}$ & $\begin{array}{c}\text { Employees } \\
(10,000)\end{array}$ & $\begin{array}{c}\text { Capital stock } \\
(100 \text { million } \\
\text { RMB })\end{array}$ \\
\hline 1978 & 75.28 & 1077.70 & 197.19 & 1994 & 318.11 & 1720.00 & 765.15 \\
\hline 1979 & 80.92 & 1104.50 & 212.30 & 1995 & 351.23 & 1748.00 & 819.88 \\
\hline 1980 & 86.79 & 1158.00 & 226.97 & 1996 & 389.55 & 1776.00 & 876.06 \\
\hline 1981 & 90.71 & 1202.20 & 241.22 & 1997 & 431.25 & 1792.00 & 938.26 \\
\hline 1982 & 98.99 & 1250.40 & 255.25 & 1998 & 481.31 & 1788.00 & 1025.51 \\
\hline 1983 & 106.21 & 1285.30 & 266.67 & 1999 & 530.92 & 1808.00 & 1126.07 \\
\hline 1984 & 125.11 & 1336.90 & 295.78 & 2000 & 586.17 & 1813.00 & 1252.79 \\
\hline 1985 & 145.73 & 1375.00 & 346.61 & 2001 & 643.60 & 1785.00 & 1385.09 \\
\hline 1986 & 158.38 & 1409.20 & 419.26 & 2002 & 715.04 & 1874.00 & 1535.92 \\
\hline 1987 & 174.19 & 1448.70 & 475.82 & 2003 & 799.42 & 1912.00 & 1770.19 \\
\hline 1988 & 210.77 & 1494.10 & 533.64 & 2004 & 902.55 & 1941.00 & 2033.79 \\
\hline 1989 & 217.70 & 1528.90 & 576.90 & 2005 & 1016.29 & 1976.00 & 2354.33 \\
\hline 1990 & 225.07 & 1576.00 & 612.13 & 2006 & 1146.37 & 2011.00 & 2850.39 \\
\hline 1991 & 241.26 & 1640.00 & 646.72 & 2007 & 1313.70 & 2041.00 & 3087.77 \\
\hline 1992 & 261.28 & 1672.00 & 676.78 & 2008 & 1518.68 & 2069.00 & 3397.70 \\
\hline 1993 & 292.90 & 1708.00 & 718.35 & \multicolumn{3}{|l|}{} & \\
\hline
\end{tabular}

Data source: Edited from data of Statistical Yearbook of Shaanxi (1980-2009). 
Table 2. The calculation reault of contribution rate of science \& technology progress. Unit: \%

\begin{tabular}{|c|c|c|c|c|}
\hline Stage (year) & $1978-1988$ & $1989-1999$ & $2000-2008$ & $1979-2008$ \\
\hline Growth rate of yield & 10.84 & 9.32 & 15.98 & 11.40 \\
\hline Growth rate of capitals & 9.47 & 6.27 & 11.72 & 9.62 \\
\hline Growth rate of labors & 3.01 & 1.54 & 1.48 & 2.13 \\
\hline $\begin{array}{c}\text { Growth rate of science \& technology } \\
\text { progress }\end{array}$ & 2.95 & 4.21 & 6.75 & 3.61 \\
\hline $\begin{array}{c}\text { Contribution rate of capitals } \\
\text { Contribution rate of labors }\end{array}$ & 66.07 & 50.85 & 55.51 & 63.83 \\
\hline $\begin{array}{c}\text { Contribution rate of science \& } \\
\text { technolgoy progress }\end{array}$ & 27.16 & 45.13 & 42.24 & 31.63 \\
\hline
\end{tabular}

